\title{
Los derechos humanos y la dignidad de los pueblos indígenas en Argentina ${ }^{2}$
}

\author{
Human rights and dignity of the indigenous people from Argentina \\ Os direitos humanos e a dignidade dos povos indigenas em Argentina
}

\section{Resumen}

En este documento se aborda el contexto en el que se logra el reconocimiento de los pueblos indígenas en Argentina y se analiza el significado de tal reforma constitucional de 1994. El objetivo que nos propusimos fue mostrar que el reconocimiento de los pueblos indígenas como sujetos de derechos, implica cambios en la fisonomía y en el comportamiento institucional de todos los niveles de gobierno, transformaciones que no se han creado de forma consecuente. Debido a estas razones, todavía no se cuenta con las condiciones para atender cabalmente los derechos humanos de los pueblos indígenas. Es decir, el fortalecimiento de la democracia en este país, requiere la puesta en marcha de políticas públicas que permitan que las autoridades hagan realidad el texto constitucional respecto a su obligación con los derechos de los pueblos indígenas y la población no indígena, desde enfoques interculturales.

Palabras clave: pueblos indígenas, derechos humanos, interculturalidad, democracia.

Recibido: 31 de marzo de 2016, evaluado: 9 de mayo de 2016, aprobado: 12 de mayo de 2016

1 Filósofa e investigadora del Centro de Investigaciones sobre América Latina y el Caribe CIALC, de la Universidad Nacional Autónoma de México UNAM. Sus investigaciones las ha centrado sobre la Filosofía de los derechos humanos y pueblos originarios en América Latina. Correo electrónico: anagro@unam.mx

2 Esta investigación fue fruto de una estancia sabática en la Universidad Nacional del Sur en Bahía Blanca, Argentina, del 1 de agosto de 2015 al 31 de enero de 2016, apoyada por el Programa PASPA de la Dirección General de Asuntos del Personal Académico de la Universidad Nacional Autónoma de México. Agradezco a la decana Lic. Silvia Álvarez la invitación para acudir a la UNS, así como todas las facilidades brindadas para mi estancia de investigación. Quiero mencionar los apoyos de Mercedes González Coll, Juan Speroni, Graciela Hernández, Angélica Mendoza, Mariana Katz y Elena Picasso en la adquisición de la bibliografía pertinente para el desarrollo de esta investigación. 


\begin{abstract}
This text addresses the context on which the acknowledgement of the indigenous people in Argentina is achieved and it analyzes the meaning of the constitutional reform of 1994 . The proposed objective was to show that the acknowledgement of the indigenous people as subjects of law implies changes in the physiognomy and institutional behavior of all the government levels, transformations that have not been created in a consequent way and because of this reasons there is still a lack in the conditions to properly attend the human rights of the indigenous people. That is to say, the strengthening of the democracy in this country requires the implementation of public policies that allow the authorities to give fulfillment to the constitutional text about the intercultural treatment between them, the indigenous people and the non-indigenous people.
\end{abstract}

Keywords: autonomy, indigenous people, coloniality of power, multiculturalism.

\title{
Resumo
}

Neste documento aborda-se o contexto no que se consegue o reconhecimento dos povos indígenas em Argentina e se analisa o significado de tal reforma constitucional de 1994. O objetivo que nos propusemos foi mostrar que o reconhecimento dos povos indígenas como sujeitos de direitos implica mudanças na fisonomía e no comportamento institucional de todos os níveis de governo, transformações que não se criaram de forma consequente e que por estas razões ainda não se conta com as condições para atender cabalmente os direitos humanos dos povos indígenas. Isto é, o fortalecimento da democracia neste país requer a posta em marcha de políticas públicas que permitam que as autoridades façam realidade o texto constitucional com respeito ao tratamento intercultural entre elas e os povos indígenas e a população não indígena.

Palavras-chave: povos indígenas, direitos humanos, interculturalidade, democracia. 


\section{Introducción}

Los derechos humanos de los pueblos indígenas son la expresión de la dignidad incluyente de las vertientes de diversidad cultural que había sido negada en la concepción eurocéntrica. Históricamente, los pueblos indígenas han resistido atentados de todo tipo contra su permanencia y pervivencia, ya sea a través de guerras genocidas o bien por las entabladas en políticas indigenistas promotoras de su asimilación y posterior extinción. Frente a estas violencias, las luchas y demandas de los pueblos indígenas a favor del respeto y protección de sus culturas han logrado la apertura de nuevos derechos humanos que condujeron a la conquista en 2007 de la Declaración de las Naciones Unidas sobre los Derechos de los Pueblos Indígenas. En este documento se reconocen sus derechos humanos, entre ellos vivir en su diferencia cultural y en articulación a la defensa de todo ser humano, porque todos los seres humanos y sus sociedades pertenecemos a una diversidad cultural. Tal Declaración proviene del tesón de estos pueblos en su reclamación de la protección de sus formas de ser culturales frente a las estrategias de los Estados por desaparecerlos, pues aun cuando no es un documento que tenga el mismo carácter vinculante que los Convenios, Pactos o Tratados, tiene un valor ético que le convierte en criterio normativo para los Estados en su actuación frente a la dignidad de todos los humanos ${ }^{3}$.

Así, los Estados que firmaron la Declaración de las Naciones Unidas sobre los Pueblos Indígenas adquieren el compromiso de levantar o crear nueva institucionalidad dirigida al cumplimiento de los derechos humanos de los pueblos indígenas, pues la finalidad de haber sido aprobada en el seno de la ONU consiste, precisamente, en inspirar vías jurídicas, políticas y éticas necesarias para la protección de la integridad humana en todas sus dimensiones, tanto individual como colectiva. Para estos propósitos, los pueblos indígenas y no indígenas tienen una función que cumplir, están llamados a formar parte de los intercambios y conocimientos mutuos en solidaridad para la coexistencia pacífica entre ellos, es decir, que los desacuerdos y disidencias que se presenten en su convivencia no impidan acuerdos solidarios. En este sentido, es que decimos que las relaciones interculturales con enfoque de derechos humanos son ideales éticos en la valoración de los programas políticos respecto a los derechos humanos de los pueblos indígenas.

Desde este panorama, en esta ocasión, analizaremos el contexto particular de los pueblos indígenas en Argentina. En primer lugar, exploraremos qué lugar tuvieron en las constituciones anteriores a la reforma de 1994, y mostraremos con ello el cambio de perspectiva que significó su reconocimiento constitucional. En un segundo momento, con base en esos datos, revisaremos las discusiones más destacadas en los últimos años sobre los derechos de los pueblos indígenas a la propiedad comunitaria.

En nuestro continente, por fin en junio de 2016, ha tenido lugar la aprobación de la Declaración Americana sobre los Derechos de los Pueblos Indígenas en el seno de la Asamblea General de la Organización de Estados Americanos. Después de 17 años de haber permanecido como Proyecto de Declaración, su afirmación por parte de los Estados miembros tendrá repercusiones en las políticas internas y externas; por ejemplo, en la protección del derecho a la consulta y en la protección de sus formas de desarrollo. Así, su influencia está porvenir y de ahí que, por ahora, celebremos su llegada dejando para otro momento la discusión con relación a los alcances mayores o menores respecto a la Declaración de la ONU de 2007.

3 Aunque en estricto sentido las declaraciones y resoluciones internacionales no tienen carácter jurídicamente vinculante, en materia de derechos humanos dichos instrumentos deben ser interpretados y aplicados en consonancia con los instrumentos convencionales de carácter general y particular, e incluso con las normas del derecho interno. De tal manera, los instrumentos declarativos y resolutivos sobre derechos humanos sí producen efectos vinculantes para los Estados, ya que estos están jurídicamente obligados a cumplir de buena fe los compromisos adquiridos en el seno de las organizaciones internacionales, atendiendo el objeto y fin de los tratados vigentes (Florentín Meléndez, 2012, p. 25). 


\section{Los pueblos indígenas y su reconocimiento en la reforma constitucional de 1994}

Para comprender el comportamiento político hacia los pueblos indígenas en América Latina, el estudio del marco jurídico es relevante en tanto que permite observar cómo es que se concibe al ciudadano, es decir, quiénes están llamados a serlo y qué derechos y obligaciones tiene como sujeto político y social.

En los estudios de Rodolfo Stavenhagen (1988 a, p.41) acerca del sitio que cobraron los pueblos indígenas en las constituciones de países latinoamericanos encontramos elementos para avizorar cuáles fueron las perspectivas ideológicas y los propósitos políticos ante ellos. Para el caso de Argentina señala este autor que en la Constitución de 1819 su artículo 129 derogó la esclavitud y el 128 dispuso lo siguiente:

Siendo los indios iguales en dignidad y en derechos a los demás ciudadanos, gozarán de las mismas preeminencias y serán regidos por las mismas leyes. (Queda excluida toda tasa o servicio personal bajo cualquier pretexto o denominación que sea). El cuerpo legislativo promoverá eficazmente el bien de los naturales, por medio de las leyes que mejoren su condición hasta ponerlos al nivel de las demás clases del Estado (Constitución de las Provincias Unidas de Sudamérica de 1819).

Recordemos que las aspiraciones políticas de las nuevas naciones en la región latinoamericana durante el siglo XIX transitaron hacia la indiferenciación entre indios y no indios por medio de la desaparición del indio, que no significó la igualdad entre ellos pues nunca se ha logrado en los hechos. Tal trama se empleó como guía de acción de los gobiernos para crear la base ciudadana al servicio de la patria, dispuesta a responder al llamado contra los enemigos de su fortaleza y unidad. De esta forma, no se dio lugar a la mención de los pueblos originarios ni a sus territorios, tampoco resultaba congruente respetar las instituciones de intercambio entre invasores y pueblos indígenas como las que se fincaron en el período colonial entre los mapuche y los invasores a través de los Parlamentos (Pinto, 2013). De este modo, la defensa de la soberanía de los nuevos estados-nación justificó las guerras totales y de exterminio contra los indios "traidores" en las guerras del Desierto (en Argentina) y de Pacificación (en Chile) a finales del siglo XIX (González, 1999).

En su planteamiento, Stavenhagen recrea los ideales de estos contornos políticos, mostrando cuál fue el modelo a seguir por los gobiernos argentinos:

El modelo político más adecuado a sus aspiraciones lo encontraron en Francia, Inglaterra y fundamentalmente en Estados Unidos. De estos tres modelos -representantes y líderes del progreso en el siglo XIX- habrían de ser tomadas sus constituciones políticas, su filosofía, su literatura y cultura en general. En definitiva, fueron los modelos conforme a los cuales se pretendía hacer una nueva historia. Estados Unidos representaba para esta generación de pensadores, la encarnación del espíritu liberal, de la modernidad y del bienestar del individuo sobre todas las cosas (1988 a, p. 29).

La generación de ilustres que pugnó por una nueva condición de los nuevos estados de la región, tuvo en la figura de Domingo Faustino Sarmiento a un gran representante, Stavengahen (1988 a, p. 29) lo centra como uno de los personajes más importantes, que planteó lo siguiente:

[...] es la Nueva Inglaterra, Norteamérica, la que debe servir de modelo a Hispanoamérica si en verdad quiere estar a la altura de los tiempos, a la altura del progreso. Ningún pueblo puede enseñarnos ya, salvo Norteamérica [...] No esperamos nada de Europa, que nada tiene que ver con nuestras razas. Algo puede venirnos de los Estados Unidos, de donde vinieron nuestras instituciones (Sarmiento, 1977, p. 225).

La Constitución argentina de 1853 , en su artículo 64 , numeral 15 , transluce el contexto ideológico-político al decir: "Corresponde al Congreso: proveer a la seguridad de las fronteras; conservar 
el trato pacífico con los indios, y promover la conversión de ellos al catolicismo" (Constitución Argentina de 1853).

En el siglo XX, en 1949, en el primer gobierno de Perón se reformó la Constitución y se sustituyó el inciso anterior. Rodolfo Stavenhagen lo refiere así:

Esta Constitución sustituye al inciso 15 del artículo 64 de la Constitución de 1853, referido a las relaciones del Congreso en el trato pacífico con los indios, y establece que las tierras no deben ser un bien de renta sino de trabajo: "que la tierra deberá ser de quien la trabaja”. Omitiéndose todo tratamiento especial en relación con los indígenas (1988 a, p.41).

El cambio constitucional, "cuyo propósito aparente era superar los déficits sociales y democráticos de la Constitución de 1853 [...] buscaría incorporar nuevos derechos sociales y económicos" (Negretto, 2015, p.156). Posteriormente, la Constitución de 1957, aclara Stavenhagen, "volvió a poner en vigencia la Constitución de 1853 enmendada en 1860" (1998 a, p. 41).

Las iniciativas de los gobiernos argentinos ante los indígenas dan lugar a un tema peculiar en la región, ya que es un país que no ha fomentado la convivencia con sus raíces indígenas, hasta muy recientemente el tema ha obtenido legitimidad social y académica. Diana Lenton describe la situación argentina de la siguiente forma:

[...] donde la negación de la propia existencia del objeto de referencia de tal política - lo indígena- ha sido un tópico, cuando no una meta, reiterada en el discurso político y en el sentido común de los últimos ciento veinte años. el convencimiento, resultado de una política de educación cívica consciente, de que "los argentinos venimos de los barcos", y el proyecto de un "crisol de razas" amable pero limitado a ciertos genotipos, hicieron parecer innecesaria la planificación o la reflexión sobre una realidad indígena que no fuera su próxima extinción o integración. por eso, parece lógico que la normativa argentina sobre pueblos originarios haya sido durante la mayor parte del siglo xx, y aún hoy en gran medida, errática e inorgánica, y más aún, ignorada por la mayor parte de la clase política (2010, p. 20).
En los años 70 del siglo xx, la "década más rica desde el punto de vista político e ideológico”, según la opinión de Angélica Mendoza, Argentina experimentó una serie de movimientos en el arte, la crítica, la movilización política y revolucionaria; el arribo de Perón en 1973, por tercera ocasión a la presidencia, y en 1974 su muerte; todos ellos, fueron hechos que coincidieron con la efervescencia de grupos indígenas:

$\mathrm{Al}$ comienzo del ' 70 algunos residentes indígenas en Buenos Aires, comenzaron a reunirse en los que se llamó la Comisión Coordinadora de Instituciones Indígenas [...] Allí se hicieron las primeras armas organizativas y establecieron una importante relación con comunidades y organizaciones del interior del país, de donde muchos de ellos provenían [...] en abril de 1972, se realizó el Primer Gran Parlamento Indígena Argentino, Futa Trawún, en la provincia de Neuquén [...] en enero de 1973 se realizó el Encuentro de Cabañaró en la Provincia del Chaco y Formosa [... en julio de 1973, tuvo lugar el Parlamento Indígena del Chaco [...] En diciembre del mismo año, se llevó a cabo el Encuentro de los Valles Calchaquíes [...] En todos estos encuentros, el temario central abarcó aquellos puntos considerados los más importantes: Tierras, Educación, Salud, Trabajo y Previsión Social y Organización y Economía. (2011, pp. 6 - 7. Énfasis propios del texto).

Siguiendo a Mendoza se puede ver que hay dos sucesos importantes en la conformación de organizaciones indígenas: la Asociación Indígena de la República Argentina (AIRA) el 25 de abril de 1975 y la Primera Conferencia Internacional de Pueblos Indios realizada en 1975 en Vancouver, Canadá, que constituyó el Consejo Mundial de Pueblos Indígenas.

Fue una época en que el Movimiento Indio, Indígena o Aborigen tuvo un importante crecimiento ideológico y protagonismo dentro del espectro de las organizaciones sociopolíticas de izquierda, con quienes a pesar de la cercanía, en ese entonces se mantenían importantes diferencias (2011, p. 8).

No obstante, la intensa participación de las organizaciones indígenas, según Diana Lenton (2010, p. 24), el indigenismo interamericano se impuso 
en el proceder de las autoridades argentinas; por ejemplo, cuando el Convenio 107 se oficializó en 1959 con la ley 14.932. No olvidemos que para los gobiernos de la región el indígena del siglo $\mathrm{xx}$ se concebía como un problema: ¿qué hacer con los indígenas que no desaparecieron? Los Estados a través del Primer Congreso Indigenista Interamericano de 1940, llevado a cabo en Pátzcuaro Mihoacán, delimitaron los lineamientos políticos definidos en su Acta Final:

El Primer Congreso Indigenista Interamericano Recomienda: 1. Que cada Gobierno establezca una agencia u oficina cuyo propósito sea concentrar la atención sobre los problemas del indio; garantizando de una manera efectiva todos los servicios del Gobierno a favor de la resolución de aquellos y constituyéndose en todo tiempo, en defensor del indio (Instituto Nacional Indigenista, 1978, p. 335).

Esta ideología política se hizo patente en Argentina:

La política indigenista se encuentra en la víspera de la emergencia - ya en los 1970- de un estilo nuevo de movilización política y de nuevas formas de represión de la misma, que cruzará la cuestión indígena. Entre 1973 y 1976, y vuelto el país a la legalidad institucional, el Ministerio de Bienestar Social continuó la tendencia de desarrollo de comunidades (Lenton, p. 24).

El golpe militar y la dictadura en Argentina (1976-1983) imprimieron uno de los capítulos más terribles y difíciles de este país y de la región, en el que se dio el "Proceso de Reorganización Nacional, todas las prácticas de agrupación política e intelectual fueron prohibidas y perseguidas, lo que también repercutió en el reconocimiento de los derechos de los pueblos indígenas" (Los derechos de los pueblos indígenas explicados para todas y para todos, 2008, p. 17). Durante este período de la dictadura se realizó una embestida a la diversidad cultural con sus propios recursos de negación:
El programa oficial en materia indigenista (anterior al retorno de la democracia) corresponde al plan de desarrollo y seguridad con los siguientes objetivos: 1) promover el poblamiento y desarrollo social de áreas de frontera; 2) promover el desarrollo de pequeñas comunidades en áreas marginadas y zonas deprimidas, y 3) la meta final es lograr la integración del aborigen, como un ciudadano más, con todos sus derechos y garantías: el principio global de la igualdad ante la ley, que mencionamos al estudiar el tratamiento constitucional de las minorías indígenas (Stavenhagen,1988 a, p. 54).

Frente a las solicitudes y demandas indígenas, la respuesta de los gobiernos se ha caracterizado por procedimientos indigenistas, por ejemplo, la Ley nacional sobre política indígena y apoyo a las comunidades aborígenes 23.302 de 1985 , que estableció la Comisión Nacional de Asuntos Indígenas responsable del Registro de Comunidades Indígenas, por las que se obtiene la personería jurídica. Su artículo 1 dice textualmente:

Artículo 1: Declárese de interés nacional la atención y apoyo a los aborígenes y a las comunidades o tribus indígenas existentes en el país, y su defensa y desarrollo para su plena participación en el proceso socioeconómico y cultural de la Nación, respetando sus propios valores y modalidades. A ese fin, se implementarán planes que permitan su acceso a la propiedad de la tierra y el fomento de su producción agraria, minera o artesanal en cualquiera de sus especializaciones, la preservación de sus pautas culturales en los dones de enseñanza y la protección de la salud de sus integrantes (Ley N. 23.302 N. ${ }^{\circ} 1985$ ).

Sin embargo, contra la incapacidad de los gobiernos argentinos en turno, ya sean democráticos o dictaduras, para dar cabida a los puntos de vista y exigencias indígenas, se ha levantado una y otra vez el propio activismo de estos pueblos. Como lo afirma Angélica Mendoza, se ha logrado a pesar de enormes resistencias de todo tipo - políticas, éticas, jurídicas, etc., de la población mayoritaria-, la visibilización de la presencia de los pueblos originarios, su condición y sus demandas como un hecho innegables en el país. Algunas de esas voces fueron las siguientes: 
[...] el Centro Kolla (CENKo) [fundado en 1979]; en 1983, el 12 de octubre, esta institución organizó la primer Marcha de repudio al festejo del mal llamado Día de la Raza [...] Movimiento Indio Peronista de la República Argentina [...] Movimiento Indio Nacionalista Justicialista $[\ldots]$ Centro Quechua Aymara [...] InAL-Tinkunaku [...] Centro de Estudios, Divulgación y Apoyo a las Culturas Indígenas [...] Agrupación Mujeres de la Tierra [...] Fundación Argentina Alexis Carrell [...] Comisión Nahuel [...] Servicio Paz y Justicia SERPAJ (Mendoza, 2011, p. 9-13).

Se comprende así que el movimiento indígena que resonó en la capital argentina, tuviera en las provincias su arraigo y su influencia jurídica con base en la fuerza y presión de la permanente acción de las organizaciones de los pueblos indígenas.

El proceso legislativo de reconocimiento de los Derechos Indígenas tuvo su origen en las provincias que sancionaron una serie de leyes específicas. Entre éstas la pionera "Ley 426 integral del aborigen" de la provincia de Formosa [1984]; seguida luego por la Ley 6373 de Salta [1986]; la 3258 del Chaco [1987]; la 2435 de Misiones [1987], luego derogada y reemplazada por la 2727 [1989]; la 2287 de Río Negro [1988], la 3657 de Chubut [1991] y, la 11078 de Santa Fe [1993] (Altabe et al., 1997, p. 9)4.

El año de 1992 fue especial porque congregó todas las manifestaciones de oposición al llamado Encuentro de Culturas, originándose la Campaña 500 años de Resistencia negra, indígena y popular.

Constituyó un hito en la historia del movimiento indígena, ya que a partir de allí el tema indígena quedó instalado definitivamente y despertó el interés y la conciencia de una gran parte de la población de la ciudad [...] La militancia de las organizaciones y comunidades indígenas, tanto del interior del país como de la ciudad de Buenos Aires, tuvieron un im- portante espacio de participación, en oportunidad de la reforma de la Constitución Nacional, realizada en 1994 (Mendoza, 2011, p. 13).

Estas organizaciones, a través de la presión constante que realizaron, lograron la inclusión de la cuestión indígena en la reforma constitucional que llevó al reconocimiento de los pueblos indígenas en Argentina en 1994. En su artículo 75, inciso 17 , reconoce la preexistencia étnica y cultural de los pueblos indígenas y en el inciso 19 acepta la pluriculturalidad del país, como podemos ver en dichos artículos que a la letra dicen:

Artículo 75, inciso 17: Reconocer la preexistencia étnica y cultural de los pueblos indígenas argentinos. Garantizar el respeto a su identidad y el derecho a una educación bilingüe e intercultural; reconocer la personería jurídica de sus comunidades, y la posesión y propiedad comunitaria de las tierras que tradicionalmente ocupan; y regular la entrega de otras aptas y suficientes para el desarrollo humano; ninguna de ellas será enajenable, transmisible ni susceptible de gravámenes o embargos. Asegurar su participación en la gestión referida a sus recursos naturales y a los demás intereses que los afectan. Las provincias pueden ejercer concurrentemente estas atribuciones.

19: [...] Dictar leyes que protejan la identidad y pluralidad cultural, la libre creación y circulación de las obras del autor; el patrimonio artístico y los espacios culturales y audiovisuales (Constitución de la República Argentina).

Respecto a los tratados internacionales de derechos humanos en Argentina que no se mencionan aquí, para tener jerarquía constitucional conforme al citado artículo 75, inciso 22 se señala: "Los demás tratados y convenciones sobre derechos humanos, luego de ser aprobados por el Congreso, requerirán del voto de las dos terceras partes de la totalidad de los miembros de cada Cámara para gozar de la jerarquía constitucional"s.

4 "Las provincias en donde existen poblaciones indígenas significativas también han desarrollado una normativa constitucional en materia indígena. Éstas son Tucumán, Chaco, Neuquén, Salta, Jujuy, Río Negro, Buenos Aires, La Pampa, Chubut, Formosa, y Entre Ríos. Varias provincias también cuentan con leyes específicas sobre diversos temas indígenas" (Anaya, 2012, p. 14). Véase la Edición especial Originarios que hemos venido citando elaborado por Angélica Mendoza, en él se da cuenta de las organizaciones indígenas más importantes que estuvieron involucradas en todos estos acontecimientos. 
La reforma constitucional respecto de los derechos de los pueblos no se introdujo en la parte orgánica, no obstante, la presencia de estos nuevos derechos impone una ética institucional para dirigir la obligación del Estado con los derechos colectivos de los pueblos indígenas. Como señala Ricardo Altabe:

La fórmula "pueblos indígenas" que aparece en el párrafo constitucional tiene como antecedentes inmediatos la Declaración de la necesidad de la reforma y el Convenio 169 de la Organización Internacional del Trabajo (OIT) aprobado por ley del Congreso de la Nación No 24071 (1997, p. 15) 2

La novedad de esta Constitución es que se refiere al sujeto pueblos indígenas con todas sus letras, lo que la coloca en un nivel superior a la ley 23-302, centrada en las comunidades aborígenes. Así, se da la apertura al pluralismo jurídico que en lo formal no corresponde con la perspectiva y enfoque eurocentrados del positivismo del siglo XIX, que algunos sectores mantienen vivo en tanto reciben sus beneficios y coinciden en sofocar o maniatar los alcances de este reconocimiento constitucional de los pueblos indígenas. Otro de los términos empleado en la Carta Magna es el de comunidad. Al respecto Alabe sostiene que con su mención se evidencia el interés que el Legislador tiene por las culturas, un aspecto relevante que destaca es el significado y sentido del término comunidad:
En resumen, el uso que se hace de la palabra "comunidad" en la Constitución Nacional recoge el sentido que le fuera impuesto en el derecho indiano, cuando era aplicada a las sociedades indígenas, al que agrega las otras denotaciones que caracterizaban a las antiguas comunidades españolas (Altabe, 1997, p. 22).

Los logros jurídicos sobre los derechos humanos de los pueblos indígenas en Argentina, tienen en contra las estrategias opositoras que persiguen la fragmentación de las comunidades y pueblos indígenas, y es que las políticas de Estado aliadas a los objetivos de las empresas nacionales y a los corporativos transnacionales, trabajan en sentido opuesto a la protección de los derechos de los pueblos indígenas como otra forma de indigenismo: neoindigenismo. Parafraseando lo que señala la Mtra. Ligia Fanny Naranjo académica y activista por la paz en Colombia, en una entrevista realizada en México (2016); la repercusión histórica de la guerra no solo con fines de dominación colonial como instrumento de lucha de un grupo social contra otro, sino como estrategia global del conservadurismo social, da origen a lo que Foucault, ha definido como el racismo de Estado que tiene su aparición a principios del siglo $\mathrm{xx}$. Este se caracteriza por el vínculo y la diferencia entre discurso racista y discurso de la guerra de razas, en el cual la sociedad va a ejercer un racismo contra ella misma, sobre sus propios elementos y sobre sus propios productos, es decir un racismo interno.

5 Artí́culo 75, inciso 22. "La Declaración Americana de los Derechos y Deberes del Hombre; la Declaración Universal de Derechos Humanos; la Convención Americana sobre Derechos Humanos; el Pacto Internacional de Derechos Económicos, Sociales y Culturales; el Pacto Internacional de Derechos Civiles y Políiticos y su Protocolo Facultativo; la Convención sobre la Prevención y la Sanción del Delito de Genocidio; la Convención Internacional sobre la Eliminación de todas las Formas de Discriminación Racial; la Convención sobre la Eliminación de todas las Formas de Discriminación contra la Mujer; la Convención contra la Tortura y otros Tratos o Penas Crueles, Inhumanos o Degradantes; la Convención sobre los Derechos del Niño; en las condiciones de su vigencia, tienen jerarquía constitucional, no derogan artículo alguno de la primera parte de esta Constitución y deben entenderse complementarios de los derechos y garantías por ella reconocidos. Sólo podrán ser denunciados, en su caso, por el Poder Ejecutivo Nacional, previa aprobación de las dos terceras partes de la totalidad de los miembros de cada Cámara.

Los demás tratados y convenciones sobre derechos humanos, luego de ser aprobados por el Congreso, requerirán del voto de las dos terceras partes de la totalidad de los miembros de cada Cámara para gozar de la jerarquía constitucional."

6 El Convenio 169 de la 0 II se sancionó el 4 de marzo de 1992, se promulgó de hecho el 7 de abril de 1992 y se publica en B. 0 el 20 de abril de 1992 (Ver: Argentina Indígena, 2015, p.7). "El día 3 de julio de 2000 tuvo lugar la Ceremonia de Depósito de la Ratificación del Convenio 169 por parte de la República Argentina, en la sede de la OIT en Ginebra. De acuerdo con ello, el mismo entra en vigencia en la jurisdicción internacional el 3 de julio de 2001" (Proyecto de Ley para dar rango constitucional al Convenio 169 de la $01 T$ en Argentina). 
Es indudable que la historia de los pueblos indígenas en Argentina tiene un punto de inflexión muy importante en la reforma constitucional de 1994. Sin embargo, o a pesar de ella, prevalecen las tendencias asimilacionistas del Convenio 107 de 1957 de la OIT en las políticas de Estado. Es por esta situación que el Convenio 169 de 1989, ratificado por Argentina en el año 2000 y que entró en vigor en 2001, no ha sido el criterio que se imponga en las relaciones entre los pueblos indígenas y el Estado argentino.

Es pertinente recordar lo que el Artículo 1 (Inciso b y número 3) del Convenio 169 de la OIT dice a la letra:

[...] b) a los pueblos en países independientes, considerados indígenas por el hecho de descender de poblaciones que habitaban en el país o en una región geográfica a la que pertenece el país en la época de la conquista o la colonización o del establecimiento de las actuales fronteras estatales y que, cualquiera que sea su situación jurídica, conservan todas sus propias instituciones sociales, económicas, culturales y políticas, o parte de ellas.

3. La utilización del término "pueblos" en este Convenio no deberá interpretarse en el sentido de que tenga implicación alguna en lo que atañe a los derechos que pueda conferirse a dicho término en el derecho internacional (Convenio 169).

No obstante que la influencia del Convenio 169 no ha sido lo esperado, tuvo el impacto suficiente para que se levantara el censo de 2001, que dio paso a la aplicación en 2004 y 2005 de la Encuesta Complementaria de Pueblos Indígenas (ECPI), "realizada por el Instituto Nacional de Estadística y Censos, que dio en ese momento una cifra de 600.329 personas pertenecientes y/o descendientes en primera generación de pueblos indígenas" (Los derechos de los pueblos indígenas explicados para todas y para todos. 2008. p.18). La Encuesta fue cuestionada porque no incluyó la pregunta por la autoidentificación como persona indígena. Otras "fuentes alternativas estiman que hay una población de hasta dos millones de personas indígenas en el país" (Anaya, 2012, pp. 10-11) y según el Registro Nacional de Comunidades Indígenas 2015, Argentina reconoce 35 pueblos indígenas.

Es importante también destacar que Argentina participó en los trabajos preparatorios y en la aprobación de la Declaración de las Naciones Unidas sobre los Derechos de los Pueblos Indígenas por la Asamblea General de ONU en 2007. Declaración en la que:

Por primera vez se reafirma que el derecho a la tierra y al territorio de los pueblos indígenas es un derecho humano por su relación intrínseca con la naturaleza. Así también, en la Declaración se les reconoce a las comunidades y las familias indígenas su rol en las responsabilidades por la crianza, la formación, la educación y el bienestar de sus niños, niñas y adolescentes. Ellos adquieren su identidad cultural como pertenecientes a un pueblo indígena, en el contexto más amplio, en la comunidad (Los derechos de los pueblos indígenas explicados para todas y para todos, 2008, p. 7).

Asimismo, de manera conjunta se afirman aquí dos derechos fundamentales: la libre determinación y la diversidad cultural:

Artículo 4. Los pueblos indígenas, en ejercicio de su derecho a la libre determinación, tienen derecho a la autonomía o al autogobierno en las cuestiones relacionadas con sus asuntos internos y locales, así como a disponer de medios para financiar sus funciones autónomas.

Artículo 31. Los pueblos indígenas tienen derecho a mantener, controlar, proteger y desarrollar su patrimonio cultural, sus conocimientos tradicionales, sus expresiones culturales tradicionales y las manifestaciones de sus ciencias, tecnologías y culturas, comprendidos los recursos humanos y genéticos, las semillas, las medicinas, el conocimiento de las propiedades de la fauna y la flora, las tradiciones orales, las literaturas, los diseños, los deportes y juegos tradicionales, y las artes visuales e interpretativas. También tienen derecho a mantener, controlar, proteger y desarrollar 
su propiedad intelectual de dicho patrimonio cultural, sus conocimientos tradicionales y sus expresiones culturales tradicionales. (ONU, 2007) ${ }^{7}$.

Es innegable que en Argentina los pueblos indígenas ya no son invisibles, la creación de leyes que tienen que ver con ellos es evidencia de su presencia, también ellas translucen la tensión que existe en el país, ya que por un lado la aparición de leyes responde a las demandas de los pueblos indígenas y, por otro, pareciera que ellas limitan el pleno despliegue de sus derechos, como más adelante lo señalaremos cuando se propuso un proyecto de ley para incluir la propiedad indígena en el Código Civil. Entre las leyes que se han dado se destacan las siguientes:

- Ley 24375 , de aprobación del convenio sobre la diversidad biológica [1994].

- Ley 24071, de aprobación del convenio 169 de la Organización Internacional del Trabajo [2000].

- Ley 23302, de política indígena y apoyo a las comunidades indígenas. Esta ley crea la Comisión Nacional de Asuntos Indígenas [1985].

- Ley 25607, de difusión de los derechos de los pueblos indígenas [2002].

- Ley 18248, sobre el nombre de las personas naturales con las reformas de las leyes 20668 , 23162,23264 y 23515.

- Ley 25517, de restitución de restos mortales de aborígenes que formen parte de museos y/o colecciones públicas o privadas [2001].

- Ley 26206, de educación nacional [diciembre de 2006].

- Ley 26331, de presupuestos mínimos de protección ambiental de los bosques nativos [promulgada el 19 de diciembre de 2007] (Los derechos de los pueblos indígenas explicados para todas y para todos, 2008, p. 24).
Las críticas de los observadores internos y externos de derechos humanos a las políticas argentinas hacen ver que a pesar de que se tiene una colección jurídica sobre pueblos indígenas, la brecha entre lo que dicen las leyes y lo que se actúa por los gobiernos es abismal, no guarda coherencia. Prevalece la condición a la que Stavenhagen nombró como "desfase en la aplicación" (Consejo Económico y Social. Foro Permanente para las Cuestiones Indígenas, p. 21).

Desde aquí, prosigamos al siguiente apartado en el que nos ocuparemos de algunas de las reflexiones que ha suscitado el derecho a la propiedad comunal indígena en el contexto reciente en este país sudamericano, ya que permite ver lo señalado anteriormente y proseguir con el contexto sui generis que mantienen las relaciones jurídicas entre los pueblos indígenas y los gobiernos.

\section{El derecho a la propiedad comunitaria indígena}

En 2012 se presentó por iniciativa de la Presidencia de la República argentina el Proyecto de Reforma de Código Civil y Comercial en el Congreso de Diputados de la Nación. Proyecto cuyas implicaciones al derecho de propiedad comunitaria indígena eran afines a su privatización, finalmente no prosperó debido a la oposición que se levantó en su contra debido a que el susodicho documento no contaba con el respaldo ni la consulta de los pueblos indígenas. Elena Picasso resume sintéticamente las razones de su inconveniencia:

El texto del proyecto de reforma reconoce a los pueblos indígenas como personas jurídicas de naturaleza privada (art. $148 \mathrm{H}$ ) junto a las mutuales, cooperativas y consorcio de propiedad horizontal,

7 Es importante tomar los alcances del derecho a la autodeterminación que son delimitados en su Art. 46:

"1. Nada de lo contenido en la presente Declaración se interpretará en el sentido de que confiere a un Estado, pueblo, grupo o persona derecho alguno a participar en una actividad o realizar un acto contrarios a la Carta de las Naciones Unidas, ni se entenderá en el sentido de que autoriza 0 alienta acción alguna encaminada a quebrantar 0 menoscabar, total o parcialmente, la integridad territorial o la unidad política de Estados soberanos e independientes" (Declaración de las Naciones Universal sobre los derechos de los Pueblos Indígenas, 2007). Lo mismo sucede con el Convenio 169 0 en las Constituciones. 
lo que contradice el reconocimiento de su preexistencia al Estado argentino. Ello supone además la imposición de reglas de funcionamiento social y político que nada tienen que ver con la organización propia de estos pueblos y comunidades y mecanismos de toma de decisiones ajenas a sus culturas (2012, p. 7).

Lo que trajo de positivo este Proyecto de Ley fue precisamente un movimiento de reacciones y reflexiones pertinentes para esclarecer el derecho de propiedad comunitaria indígena. Para abordar este asunto elegimos las aportaciones del volumen: Dossier Propiedad comunitaria indígena (Kosovsky y Ivanoff, 2015), publicado con el apoyo de la Asociación Argentina de Abogados/as de Derecho Indígena - AADI - y la Cátedra Libre de Pueblos Originarios de la Universidad Nacional de la Patagonia San Juan Bosco, desde ellas ilustraremos algunas de las repercusiones más importantes que conlleva la propiedad comunitaria indígena.

En primer término, las opiniones de Juan Manuel Salgado centran y ubican la temática, ya que propone claves para comprender la situación en la que se encuentra el derecho de propiedad indígena "sobre las tierras que tradicionalmente ocupan", en tanto que no ha sido resuelto y es poco común que se den resoluciones judiciales y administrativas a su favor, es por ello que se promulgó en noviembre de 2006:

La Ley 26.160: Declárase la emergencia en materia de posesión y propiedad de las tierras que tradicionalmente ocupan las comunidades indígenas originarias del país, cuya personería jurídica haya sido inscripta en el Registro Nacional de Comunidades Indígenas u organismo provincial competente o aquéllas preexistentes (ONU, 2007).

Salgado sostiene que el Convenio 107 de la OIT, ratificado en 1960 en Argentina, no se aplicó ni respetó la propiedad comunitaria indígena porque, aun cuando el espíritu de este documento haya sido asimilacionista en él, se hace mención de la propiedad indígena, a diferencia de la Ley 23.302 de 1985 que no reconoció la propiedad ancestral de los pueblos originarios indígenas, pero sí de la constitución de la personería jurídica para obtener un trato institucional. Para apoyar su argumento trae a colación el punto de vista de Germán Bidart Campos, quien opinó sobre la interpretación de la letra constitucional que dice: corresponde al Congreso "reconocer la personería jurídica de sus comunidades y la propiedad comunitarias de las tierras que tradicionalmente ocupan", afirmando que no se necesita una ley específica para su operatividad sino que "esa norma establecía derechos que debían ser reconocidos sin ningún trámite previo (Dossier Propiedad comunitaria indígena, Salgado, 2015, p. 2).

Tales afirmaciones del gran jurista Bidart Campos cobran una singular importancia para los derechos de autonomía, los espacios y los lugares de la propiedad comunitaria indígena, pues es la comunidad "el donde", el lugar, el sitio, desde el que se reclama el derecho de autonomía y esto es lo que causa tanto desconcierto y oposición, ya que su tratamiento y aceptación por el gobierno significaría que debe proteger distintas dimensiones de propiedad: la privada de los individuos, la de las corporaciones y la comunitaria de los pueblos indígenas. Es frecuente, por otro lado, la desconfianza sobre la institucionalidad de la personería jurídica como el camino indicado para la pertinente atención del derecho de propiedad comunitaria indígena, pues se le ha venido dando un trato dentro de la percepción gubernamental monocultural. En este sentido es que la Comisión de Expertos de la OIT envió en 2007 al gobierno de Argentina la siguiente observación:

La Comisión de Expertos notó que en algunas provincias, las comunidades indígenas tramitan su personería jurídica como asociaciones civiles. La Comisión solicitó al Gobierno que despliegue esfuerzos para que las comunidades puedan ser reconocidas como comunidades indígenas "ya que la asociación civil parece suponer la constitución de algo nuevo y no responde exactamente al principio del Convenio de reconocimiento de una realidad preexistente. (Los derechos de los pueblos indígenas y tribales en la práctica- una guía sobre el Convenio Núm. 169 de OIT, p. 11). 
Esta observación tiene como foco de preocupación el que a la personería jurídica de los pueblos indígenas se le dé la equivalencia a la apertura y el trámite para formar una sociedad civil, en tanto estamos hablando de pueblos indígenas preexistentes a la formación del Estado nación y que son sujetos de derechos.

En este tenor de ideas, es pertinente acudir nuevamente a las palabras de Juan Manuel Salgado:

La propiedad indígena tiene características diferenciales de la propiedad civil, es más el mismo término "propiedad" resultaría inadecuado si no fuera que es sumamente útil para que los miembros de la cultura dominante comprendan que es un derecho difícil de soslayar. Sin embargo son raras las resoluciones judiciales y prácticamente inexistentes las decisiones administrativas que reconozcan este derecho. Tan es así que en el año 2006 se dictó una ley nacional, No 26.160, que declara "en emergencia" las tierras de posesión indígena y "suspende" todo desalojo por el término de cuatro años [se ha renovado su vigencia dos períodos más hasta 2017], lo cual no tendría ningún sentido si hubiera reconocimiento de la propiedad tal como aparece en la Constitución (Dossier Propiedad Comunitaria Indígena, pp. 1-2).

Fernando Kosovsky explica que existen tres falencias en la ley 23.302:

Prescinde de las culturas como categorías esenciales que distinguen colectivos humanos; Ignora al "Pueblo" indígena como sujeto de derecho [...] Por esta misma razón, omite la categoría de "territorio"; anula de hecho la libre determinación (2015, p. 177-178).

Por lo tanto, el cumplimiento de este derecho a la propiedad comunitaria indígena conduciría a otro momento en las relaciones entre el Estado argentino y los pueblos indígenas. En esta causa es pertinente traer a mención el emblemático caso que ha constituido la sentencia de la Corte Interamericana de Derechos Humanos de 2001: Awas Tingni contra Nicaragua, en el que se resolvió que el derecho de propiedad también incluye el derecho de los pueblos indígenas a sus tierras "por encima de cualquier norma civil interna".
Otro ejemplo destacado por estos autores es el caso Sawhoyamaxa contra Paraguay, que ha sido paradigmático en la región para llevar a cabo el cumplimiento del derecho a la propiedad indígena.

Por su lado, Silvina Ramírez señala que para que el Estado responda a las demandas de los derechos de los pueblos indígenas y a la propiedad de sus territorios es necesario que trascienda sus bases monoculturales sobre las que fincó el rechazo de las raíces de diversidad cultural. Propone que el Estado cumpla los siguientes retos:

Gestionar junto con los Pueblos indígenas la explotación de esos recursos (bosques, petróleo, las reservas del agua, los recursos mineros).

Consultar a los Pueblos indígenas sobre cualquier medida que tome sobre la disposición de dichos recursos.

Preservarlos, ya que constituyen la base de la economía de los pueblos.

Obtener el consentimiento previo, libre e informado de los pueblos indígenas, luego de la referida consulta. (Dossier Propiedad comunitaria indígena, 2015, Ramírez, p. 15)

Es decir, la posibilidad de fomentar las relaciones de paz y respeto para los derechos de los pueblos indígenas, estaría dada, entonces, en el cambio de enfoque del accionar del gobierno en todos los niveles de su autoridad a favor de cumplir con los criterios de interdependencia e indivisibilidad de los derechos humanos.

Por estas razones, las propuestas de Silvina Ramírez son relevantes para centrar la situación de este derecho en Argentina, lo afirma del siguiente modo: "Uno de los desafíos en el futuro inmediato es la elaboración de una ley especial que regule la propiedad comunitaria indígena, adecuando su contenido a lo dispuesto por las herramientas jurídicas internacionales y a la propia Constitución nacional" (Ramírez, 2015, p. 18).

El porvenir de la interculturalidad está en simientes en Argentina, se están dando acciones desde 
distintos lugares y trincheras en los que las organizaciones indígenas no están solas, sino apoyadas por académicos, intelectuales, activistas de derechos humanos, por ejemplo SERPAJ Argentina. También tenemos conocimiento de iniciativas para conformar programas de educación intercultural para toda la población no sólo para la indígena y dirigida a la educación universitaria, como la que propone Alcira Argumedo (2015), que manifiesta la preocupación por cambiar las relaciones de los gobiernos con los pueblos indígenas, como premisas de fortalecimiento de la democracia argentina. Por esto mismo, cuando se pretenda decir que los derechos humanos pertenecen a valores de tiempos pasados, o hablar de la condición post-derechos humanos, se corre el peligro de perder lo ganado a favor de la administración de los "derechos humanos" por corporaciones o por facciones confe-sionales y no por bases democráticas. Es decir, las aspiraciones políticas de los derechos humanos son de otra especie: requieren arraigo en prácticas de respeto de la dignidad humana protegidas por el poder político que reconozca sus propios límites para aplicarlos en bien de sus obligaciones frente a ella.

\section{Reflexiones Finales}

La transformación que ha experimentado la sociedad argentina en el marco jurídico del reconocimiento de los derechos humanos de los pueblos indígenas muestra que no es posible mantenerse en la negación de sus raíces de diversidad cultural. Este es el espíritu de la reforma constitucional de 1994, que sin duda cobra la forma de un gran acontecimiento jurídico, pero se ha quedado en el aspecto formal y abstracto, pues todavía prevalecen las políticas insensibles a los reclamos indígenas y, en ocasiones, atentatorias a su integridad y dignidad comunitarias. El armazón que se le dio a la personería jurídica para reconocer las tierras a los indígenas, si bien son, por un lado, formas de control y vigilancia, ha sido el recurso de los civiles como un elemento jurídico legal que dota de herramientas para la defensa y reclamación de la propiedad y posesión de la tierra, ambas cosas son datos que no se pueden negar. Lo que sí se dice que es indispensable hacer es revisar el enfoque que arma la trama legalista de la institución de la personería jurídica para que no tergiverse el reconocimiento de los pueblos indígenas y se nulifique su comprensión como preexistentes al Estado nación. Como sabemos, los derechos humanos son valores de nuestro tiempo abiertos a la diversidad cultural y a los problemas concomitantes como la destrucción del planeta, la nueva esclavitud, el tráfico de órganos y todas las formas del crimen organizado. Para enfrentarlos desde posiciones de paz y de rechazo a toda transgresión de la vida y dignidad humanas es indispensable que existan bases de interculturalidad en las distintas formas de asociaciones y convivencia políticas.

Nuestra región que es muestra de la diversidad cultural humana y de búsqueda de derroteros para protegerla también es ejemplo de que la democracia todavía no ha enrizado lo suficiente para asegurar los derechos humanos ya que los fantasmas de la violencia y la intolerancia no han abandonado a los gobiernos democráticos. De ahí la necesidad de fortalecer y profundizar las relaciones entre las distintas culturas y las formas democráticas de poder, puesto que no contamos con otros criterios distintos de los derechos humanos que hablen en nombre de toda la humanidad para poner límites a los poderes de los gobiernos frente a la intraspasable dignidad de los humanos en su diversidad cultural.

En Argentina, los límites y alcances de los poderes políticos a favor de la defensa de los derechos de los pueblos indígenas son asuntos con fronteras nebulosas. Ya no es tiempo para seguir transando su integridad, ni para el regateo de su inclusión como parte de los grandes valores de la dignidad de todos los humanos. El trato justo, los diálogos interculturales, el pluralismo jurídico y las respuestas plenas a las exigencias de protección de la diversidad cultural, son caminos para afianzar derroteros democráticos en contra de la fragmentación y desaparición de la diversidad cultural.

Sin duda, la compleja realidad política de nuestra región, situada en estos momentos por una oleada de nuevas derechas, cobra urgencia el respeto y puesta en marcha de la perspectiva interdependiente de los derechos humanos. 


\section{Referencias}

Aguilar, G., Lafosse, S., Rojas, H., \& Steward, R. (2010). South/North Exchange of 2009The Constitutional Recognition of Indigenous Peoples in Latin America, Pace Int'l L. Pace international law review online companion, Rev. Online Companion. Recuperado de: http:// digitalcommons.pace.edu/cgi/viewcontent.cg $i$ ?article $=1017 \&$ context $=$ pilronline

Altabe, R., Braunstein, J., González, J., J. Braunstein. (1997). Derechos Indigenas en la Argentina. Reflexiones sobre conceptos y lineamientos generales contenidos en el art. 75 inciso 17 de la Constitución Nacional. Chaco: Equipo Nacional de Pastoral Aborigen (Cuadernos ENDEPA 3).

Anaya, J. (2012). La situación de los pueblos indígenas en Argentina. Informe del Relator Especial sobre los derechos de los pueblos indigenas. Copenhague: Grupo Internacional de Trabajo sobre Asunto Indigenas IWGIA. Recuperado de: http://www.iwgia.org/iwgia_files_publications_files/0587_ANAYA_Informe_final. pdf

Argentina, Ministerio de Justicia y Derechos Humanos. (1985). Ley N. ${ }^{\circ} 23.302$ sobre Política Indigena y apoyo a las Comunidades Aborigenes. Objetivos. Comunidades Indígenas. Instituto Nacional de Asuntos Indigenas. Adjudicación de Tierras. Planes de Educación, Salud y Vivienda. Recuperado de: http://www.infoleg.gov.ar/infolegInternet/anexos/20000-24999/23790/ norma.htm

Argentina. Ministerio de Justicia y Derechos Humanos. (2015). Argentina Indígena. Participación diversidad. Construyendo igualdad. Compilación legislativa. Buenos Aires: Instituto Nacional de Asuntos Indigenas. Recuperado de: http://www.jus.gob.ar/media/2957543/ argentina_indigena_web.pdf

Argentina. (s.f) Proyecto de Ley para dar rango constitucional al Convenio 169 de la OIT en Argentina. Recuperado de: http://www.alertanet.org/pi-arg-conv169.htm

Argumedo, A. (2015). Proyecto Universidad Nacional Intercultural Indigena [Versión electrónica].
Recuperado de: https://universidadindigena. wordpress.com/category/noticias/

Becerra, A. (1992). Caja de herramientas sobre el derecho a la consulta en el gran Legislación sobre pueblos indigenas. Normas nacionales y provinciales. [Versión electrónica]. Recuperado de: www.tierraviva.org.py/../Legislación-argentina -sobre-pueblos-indígenas.pdf

Clavero, B. (2008). Geografía Juridica de América Latina. Pueblos Indigenas entre constituciones mestizas. México: Siglo XXI.

Constitución Argentina de 1853. [Versión electrónica] Recuperado de: http:// c yt - ar.com.ar/cyt-ar/index.php/ Constituci\%C3\%B3n_Argentina_de_1853

Constitución de la República Argentina. Recuperado de: http://infoleg.mecon.gov.ar/ infolegInternet/anexos/0-4999/804/norma. htm

Constitución de las Provincias Unidas de Sudamérica de 1819. [Versión electrónica] Recuperado de: https://es.wikisource. org/wiki/Constituci\%C3\%B3n_de_la_ Naci\%C3\%B3n_Argentina_(1819)

Daes, E. (1997). Protección del Patrimonio de los Pueblos Indígenas. New York: Naciones Unidas. Recuperado de: http://www.corteidh. or.cr/tablas/r912.pdf

De Sousa Santos, B. y Grijalva, A. (Ed.). (2012). Justicia Indigena, plurinacionalidad e interculturalidad en Ecuador. La Paz: Abya YalaFundación Rosa Luxemburgo.

De Sousa Santos, B. y Rodríguez, J. (Ed.). (2012). Justicia Indigena, plurinacionalidad e interculturalidad en Bolivia. Quito: Abya YalaFundación Rosa Luxemburgo.

Domingo, F. (1977). Caracas: Biblioteca Ayacucho. Ecuador. Instituto Nacional de Estadísticas y Censos. Encuesta Complementaria de Pueblos Indígenas. (2004-2005). Recuperado de: http://www.indec.gov.ar/micro_sitios/webcenso/ECPI/index_ecpi.asp

Fondo de las Naciones Unidas para la Infancia (UNICEF). (2008). Los derechos de los pueblos indígenas explicados para todas y para 
todos. La Declaración de las Naciones Unidas sobre los derechos de los pueblos indigenas y su relación con normas fundamentales del derecho internacional. Argentina. Recuperado de: http://www.unicef.org/argentina/spanish/derechos_indigenas.pdf

Foucault, M. (2002). Defender la Sociedad. Curso en el College de France (1975 - 1976). México: Fondo de Cultura Económica.

Ginebra. Oficina del Alto Comisionado de las Naciones Unidas para los Derechos Humanos. (2008). Derechos Terrorismo y la Lucha contra el Terrorismo. Folleto Informativo $\mathrm{N}^{\circ} 32$.

González, M. (1996). Frontera, cultura de contacto. ¿Coexistencia equilibrada o conflicto encubierto? En: Araucania y Pampas. Un mundo fronterizo en América del Sur. Jorge Pinto (Ed.). Temuco: Ediciones Universidad de la Frontera.

González, M., (Comp.). (1999). Viejos y Nuevos Estudios Etnohistóricos. Bahía Blanca: Universidad Nacional del Sur.

Henderson, H. (2004). Los Tratados Internacionales de Derechos Humanos en el orden interno: La Importancia del Principio pro homine. Recuperado de: www.juridicas.unam.mx

Hitters, J. (s.f.). Reforma de la Constitución Argentina y los Tratados sobre Derechos Humanos a 20 años de su vigencia. [Versión electrónica]. Recuperado de: http://perso.unifr.ch/ derechopenal/assets/files/obrasportales/ op_20141108_03.pdf

Instituto Nacional Indigensita.30 años después. Revisión crítica. (1979). México, D. F., México Indígena. Órgano de Difusión del Instituto Nacional Indigenista, Número Especial de Aniversario, diciembre.

Instituto Nacional Indigenista. INI 30 AÑOS DESPUÉS. Revisión Crítica. (1978). México Indigena Órgano de Difusión del Instituto Nacional Indigenista. Número Especial de Aniversario.

Kosovsky, F. (Comp.). (2015). Dossier. Propiedad Comunitaria Indigena. Chubut: Universitaria de la Patagonia.

Lenton, D. (2010). Política indigenista argentina: una construcción inconclusa. En Aportes de los pueblos originarios a la educación en el
Bicentenario. Nutram N. (Ed.) Buenos Aires. (pp. 20-27).

Los Derechos de los Pueblos Indígenas y Tribales en la práctica-una guía sobre el Convenio Núm. 169 de la OIT (PRO 169). (2009). Departamento de Normas Internacionales del Trabajo. Recuperado de: http://www.aecid. es/Centro-Documentacion/Documentos/ Publicaciones \% 20 A E C I D / 6.\% 20 Implementaci\%C3\%B3n\%20Convenio\%20 169\%20-\%20ILO.pdf

Mapa 2015 de Pueblos Originarios en la Argentina. Secretaría de Derechos Humanos. [Versión electrónica] Recuperado de: http://www.jus. gob.ar/media/2940192/mapa_pueblos_nuevo-_1_.jpg

Meléndez, F. (2012). Instrumentos Internacionales sobre Derechos Humanos Aplicables a la Administración de Justicia. (8a ed). Bogotá: Fundación Konrad Adenauer-Fundación. Editorial Universitaria del Rosario. Recuperado de: http://www.kas.de/wf/doc/kas_332541522-4-30.pdf?130109170856

Mendoza, A. (2011). Memoria de los Pueblos Originarios en la Ciudad de Buenos Aires. Cómo se organizó y fortaleció el Movimiento Indio en Buenos Aires. En: Originarios. Vocero del Equipo Pueblos Originarios Servicio Paz y Justicia Argentina. Buenos Aires.

Naciones Unidas. (2007). Declaración de las Naciones Universal sobre los derechos de los Pueblos Indígenas. Recuperado de: http:// www.un.org/esa/socdev/unpfii/documents/ DRIPS_es.pdf

Naciones Unidas. Consejo Económico y Social. Foro Permanente para las Cuestiones Indígenas $14^{\circ}$ Período de Sesiones. E/C.19/2015/8. Recuperado de: cendoc.docip.org/collect/cendocdo/index/assoc/..dir/ PF15optionalprot_es.pdf

Naciones Unidas-CEPAL. (2014). Los Pueblos Indígenas en América Latina. Avances en el último decenio y retos pendientes para la garantía de sus derechos. Recuperado de: http://repositorio.cepal.org/bits$\mathrm{tream} / \mathrm{h}$ a ndle/11362/37050/ S1420783_es.pdf?sequence $=4$ 
Negretto, G. (2015). La politica del cambio constitucional en América Latina. México: Fondo de Cultura Económica.

Picasso, E. (2012). Pueblos, Indigenas y Anteproyecto de Reforma del Código Civil. [Versión electrónica]. Recuperado de: odhpi.org/wp-content/ uploads/2012/11/elena-picasso.docx

Pinto, J. (2003). La formación del Estado y la nación, y el pueblo mapuche. De la inclusión a la exclusión. (2a ed.). Santiago: DI- BAMCentro de Investigaciones Diego Barros Arana. Recuperado de: http://www.memoriachilena. cl/archi- vos2/pdfs/MC0027516.pdf

Salgado, J., y María Micaela Gomiz. (Ed.). (2010). Convenio 169 de la O.I.T. sobre Pueblos Indigenas. Su aplicación en el derecho interno argentino. Neuquén: ODHPI Recuperado de: http://www.iwgia.org/iwgia_files_publications_files/ILO_argentina_text.pdf

Stavenhagen, R. (1998 a). con la colaboración de Tania Carrasco, Luis Müller, Mario Ibarra, Carmen Junqueiro, Salomón Nahmad; Luis Alverto Padilla, Eunice Paiva, Nemesio J. Rodríguez y Stefano Várese. Derecho indígena y derechos humanos en América Latina.
México. Instituto Interamericano de Derechos Humanos-El Colegio de México. Recuperado de: http://www.iidh.ed.cr/comunidades/diversidades/docs/div_docpublicaciones/indice\%20derecho\%20indigena.htm

Stavenhagen, R. (1988 b). La diversidad Cultural en el Desarrollo de las Américas. Los estados nacionales en Hispanoamérica. El Colegio de México. Recuperado de: www.oas.org/udse/ espanol/documentos/1hub8.doc

Stavenhagen, R. (2008). Pueblos indigenas y sus derechos. Informes Temáticos del Relator Especial sobre la situación de los Derechos Humanos y las Libertades fundamentales de los Pueblos Indigenas del Consejo de Derechos Humanos de la organización de las Naciones Unidas. México: UNESCO. Recuperado de: www.unescomexico.org

The concept of indigenous peoples. (2004). Department of Economic and Social Affairs. Division for Social Policy and Development Secretariat of the Permanent Forum on Indigenous Issues. Recuperado de: http:// www.un.org/esa/socdev/unpfii/documents/ workshop_data_background.doc 